LIBRI

www.libridergi.org

Kitap Tanıtımı, Eleştiri ve Çeviri Dergisi

Journal of Book Notices, Reviews and Translations

Volume I (2015)

M. HAKMAN, Kapadokya'da Zeus Kültü. İstanbul 2014. Arkeoloji ve

Sanat Yayınları, 229 sayfa (13 harita, 36 levha). ISBN: 9786053963257

Pınar ÖZTÜRK

Libri: Kitap Tanıtımı, Eleştiri ve Çeviri Dergisi'nde bulunan içeriklerin tümü kullanıcılara açık, serbestçe/ücretsiz 'açık erişimli' bir dergidir. Kullanıcılar, yayıncıdan ve yazar(lar)dan izin almaksızın, dergideki makaleleri tam metin olarak okuyabilir, indirebilir, dağıtabilir, makalelerin çıktısını alabilir ve kaynak göstererek makalelere bağlantı verebilir.

Libri, uluslararası hakemli elektronik (online) bir dergi olup değerlendirme süreci biten makaleler derginin web sitesinde (www.libridergi.org) yıl boyunca ilgili sayının içinde (Volume I: Ocak-Aralık 2015) yayımlanır. Aralık ayı sonunda ilgili yıla ait sayı tamamlanır.

Dergide yayımlanan eserlerin sorumluluğu yazarlarına aittir.

Künye M. HAKMAN, Kapadokya'da Zeus Kültü. İstanbul 2014. Arkeoloji ve Sanat Yayınları, 229 sayfa (13 harita, 36 levha). ISBN: 9786053963257 Tanıtan: Pınar ÖZTÜRK, Libri I (2015) 17-22. DOI: 10.20480/lbr.2015115456

Geliş Tarihi: 05.08.2015

Kabul Tarihi: 07.08.2015

Online Yayın Tarihi: 26.12.2015

URL: http://dx.doi.org/10.20480/lbr.2018115456

Editörya Phaselis Project

www.phaselis.org 


\author{
M. HAKMAN, Kapadokya'da Zeus Kültü. İstanbul 2014. \\ Arkeoloji ve Sanat Yayınları, 229 sayfa (13 harita, 36 levha). \\ ISBN: 9786053963257
}

\title{
Pınar ÖZTÜRK*
}

Inanç kavramı, insanoğlu var olduğundan beri varlığını sürdürmektedir. Çoktanrılı inançtan tek tanrılı inanca geçilen süreçte insanoğlu, ölüme ve doğa olaylarına karşı verdiği tepkiler sonucunda tanrılar dünyasını yaratmıştır. Bu geçiş süreci içerisinde incelemek gerekirse, M.Ö II. binlerden itibaren gelişimini sürdüren Hellen dininde, tanrılar antropomorfik olarak biçimlenmekte ve bu dini yapılaşma içinde mitoslarıyla birlikte Olymposlu tanrılara ve de özellikle Zeus'a Hellen Panteon'unda çok önemli bir rol biçilmektedir.

Zeus bu güne kadar bir Hellen tanrısı olarak bilinse de, kökeni tartışmalıdır. Mitolojik sahnelerde tanrının Anadolu'daki kimlikleri ve toplumdaki yeri, perde arkasında bırakılmıştır. Bu araştırma, perde arkasında kalan tüm bilinmeyenlerle birlikte, Zeus'un Anadolu'daki zengin kült yapısının ve çeşitliliğinin Kapadokya Bölgesi'nde de görüldüğünü okuyucuya aktarmaktadır. Aynı zamanda bu bölgede tanrının farklı epitetler altındaki tapınımını ve kimliğini irdeleyerek Zeus'u kapsamlı bir şekilde tanıtmaktadır.

Aksaray Üniversitesi Arkeoloji bölümünde öğretim üyesi olan Yrd. Doç. Dr. Meral Hakman'ın kaleme aldığı eserin ilk kısmında, Kısaltmalar Listesi (9-11), Haritalar Listesi (11-13) ve Levhalar Listesi (13-17) olmak üzere 3 ayrı listeye yer verilmektedir. Çalışma, bu listelerin hemen ardından Önsöz (17-19) ve Giriş (17-19) kısmıyla devam etmektedir. Hakman'ın ele aldığı bu araştırma Eskiçağ’da Zeus Kültü (25-37), Kapadokya (37-69), Pers Kökenli Zeus Kültleri (121-141), Bir Sıfattan Kaynaklanan Zeus Kültleri (141-161), Bir Antroponym ve Toponymden Kaynaklanan Zeus Kültleri (161-197) olmak üzere 6 ana bölümden oluşmaktadır. Bu bölümler ise, Sonuç (197-201) ve Kaynakça (201) ile noktalanmaktadır.

Hakman çalışmasının Önsöz'ünde (17-19) "bölgedeki Zeus kültünün tanrıya verilen epitetler yolu ile ele alındığını, her bir epitetin kökeni belirlendikten sonra ise Anadolu'daki yayılımlarının arkeolojik, epigrafik ve nümizmatik veriler yoluyla açıklanarak bölgedeki yapısının incelendiğini" belirtmektedir.

Yazar bu araştırmasında, Kapadokya Bölgesi'ndeki Zeus kültünü söz konusu disiplinlerin sağladığı verilere ve modern pek çok kaynağa dayandırmakta ve eserini bu kültlerin çeşitliliğinin ardında yatan siyasi değişimler ile egemenlik mücadeleleri üzerine temellendirmektedir.

Eserin Giriş'inde (19-25) bu çalışmanın Konusu'nu (19-20) 'Kapadokya'da Zeus Kültü'nün

\footnotetext{
* M.A., Akdeniz Üniversitesi, Akdeniz Uygarlıkları Araştırma Enstitüsü, Akdeniz Eskiçağ Araştırmaları Anabilim Dalı, Antalya. pinar.ozturk.1988@gmail.com
} 
oluşturduğu belirtilmekte ve araştırmanın konusu dâhilinde altı ana başlık kısaca tanıtılmaktadır. Antikçağ yazarlarından edinilen bilgiler ışığında Zeus kültleri kökenlerine göre sınıflandırılmakta, epitetleri değerlendirilmektedir. Bu değerlendirme sonucunda varılan noktada Zeus kült yapısı bölgenin diğer kentleri ve Anadolu' daki örnekleri ile karşılaştırılmaktadır.

Eserde tanrının kültüne ait bilimsel veriler belirlenerek siyasi haritanın değişmesine bağlı gerçekleşen gelişime ve bölgedeki Zeus kimliğine epitetler yolu ile açıklama getirilmeye çalışılmaktadır. Kapadokya'nın inanç yapısı, hakimiyeti altında bulunduğu medeniyetler ile beraber şekillenmektedir. Bölgenin dini anlamda yaşadığı en büyük etkileşim, Kapadokya'nın Perslere bağlı bir satraplık olması ile başladığı için bu dönemden itibaren yerli kültler Pers tanrıları ile tanışarak bütünleşir. Özellikle onların Ahura Mazda ve Mithra gibi tanrıları, Hititlerden bu yana varlığı bilinen en eski kült olan dağ tanrı Argaios ve Zeus ile bir tutulur.

Hakman eserinin Amaç (20-21) kısmında "her bir epitetin özellikle Anadolu'nun diğer bölgelerindeki yapısı ile karşılaştırma yoluna gidilerek baş tanrı Zeus konusunda Kapadokya’nın inanç sistemini ortaya çıkartmak" olduğunu ifade etmektedir. Bu bağlamda çalışmanın esasen temelini Kapadokya'da Zeus kültü konusunun bir bütün halinde ortaya konulması oluşturmaktadır.

Eserin Araştırma Yöntemi (21-22) konu, kapsam ve amaçlar doğrultusunda, bu alanla ilgili bilimsel veriler, antik kaynakların aktardığı bilgiler, Kapadokya ile ilgili elde edilen veriler Anadolu'nun bölgelerindeki örnekleriyle karşılaştırılarak sistematik bir düzen çerçevesinde oluşturulmaktadır.

Her başılı altında yapılan genel değerlendirmede kültlerin köken özellikleri, epitetlerin anlamları ve Zeus'a yüklenen tanrısal ifadeler, kutlanan festivaller ve bunların içerikleri sözü edilen bilimsel veriler eşliğinde özetlenmektedir. Zeus epitetlerinin genel özelliklerinin ve Kapadokya'ya özgü özelliklerinin belirlenmesi yoluyla her bir kült, benzer ve farklı özellikleri vurgulanarak değerlendirilmektedir. Böylece tanrının bölgedeki inanç kronolojisi açığa çıkarılmakta, bu anlatımın ise kronolojik bir çizgiyi takip ettiği anlaşılmaktadır.

Kapsam ve Sınırlııklar'ın (22-25) belirlenmesi konunun ana hatlarının daha iyi anlaşıması bakımından önem kazanmaktadır. Kapadokya Bölgesi'nin sınırları ve hâkimiyetleri en erken tarihlerden itibaren değişkenlik göstermektedir. Kapsam ve Sınırılıklar (22-25) bu değişkenlik temel alınarak anlatılmaya çalışımaktadır.

Altı ana bölümün ilki olan Eskiçağ'da Zeus Kültü (25), 1.1 Zeus: Mitoloji (25-30), 1.2 Zeus'un Epitetlerinin Genel Özellikleri (30-34), 1.3 Araştırma Tarihçesi (34-37), olmak üzere 3 alt başlıktan oluşmaktadır.

Eskiçağ 'da yoğun bir şekilde tapınım gören tanrı öncelikle Zeus: Mitoloji (25-30) alt başlığıyla birlikte mitolojik olarak tanıtılmaya çalışımıştır. Daha sonra ise tanrının adına ilişkin açıklamalara kısaca değinilmekte, tanrının ikonografisine bakılarak mitoloji üzerinden epitetlerinin anlamları değerlendirilmektedir. Yazar epitetlerin, tanrıların asıl görevlerini pekiştirmek ya da onlara farklı işlevler yüklemek için insanoğlunun kendi çıkarları adına verilmiş sıfatlar olduğuna vurgu yapmaktadır. Bu anlamda Zeus'un Epitetlerinin Genel Özellikleri (30-34), yerleşimin veya toplulukların genel özelliklerine göre sınıflandırımış bir şekilde okuyucuya aktarılmaktadır.

İkinci ana bölüm Kapadokya (37) başlığı ile 2.1 Coğrafi Çerçeve (37-43). 2.2 Tarihsel Çerçeve (43-66), 2.3 Araştırma Tarihçesi (66-69) alt başlıklarından oluşmaktadır.

Tanııın bölgedeki tapınımının sebepleri bölgenin kendisi ve tarihçesiyle doğru orantılıdır. 
Bölgenin Coğrafi Çerçeve'si (37-43) Kapadokya'nın sınırları ve sınır değişkenliği hakkında bilgi sunarken, Tarihsel Çerçeve'si (43-66) Kapadokya'nın tarihinin Paleolitik Çağ'a kadar uzanması sebebiyle okuyucuyu zaman yolculuğuna çıkarmaktadır. Bu tarihsel sınırlamalar içerisinde belli bir kronolojik düzenin izlendiği gözlemlenmektedir. Bu kronolojik çizgide eser, Kapadokya hangi dönemlerde kimlerin egemenliği altındaydı, hangi halklar buradan göç etti, hangileri yerleşimde bulundu gibi daha birçok soruya cevap vermektedir.

Zeus ile ilgili bu önemli araştırmanın üçüncü bölümü bir ana başlık, beş alt başılk, altı yan başlık ve bunlara bağlı yedi yan başlıktan oluşmaktadır. Bu bölüm Pers Kökenli Zeus Kültleri (6970) ana başlığı altında 3.1 Zeus Ahura Mazda Kültü (70), 3.1.1. Ahura Mazda ve Dini (70-76), 3.1.2. Kapadokya'da Zeus Ahura Mazda Kültü (76-80), 3.1.2.1 Bünyan Altarı (80-84), 3.1.2.2. Arabsun Yazıtı (84-87), 3.1.2.3. Kirdir Yazıtı (87-93), 3.2. Zeus Mithra Kültü (93), 3.2.1. Mithra ve Inana (93-97), 3.2.2 Kapadokya'da Zeus Mithra Kültü (97-98), 3.2.2.1. Farasa Yazıtı (98-99), 3.2.2.2. Tyana Yazıtı (99-101), 3.2.2.3. Kayseri Yazıtı (101-102), 3.2.2.4. Camilhöyük Mithra Maskesi (102-104), 3.3. Kapadokya'da Thymnasalı Zeus ve Zeus Pharnaouas Kültü (104-107), 3.4. Zeus Stratios Kültü (107-11), 3.4.1. Kapadokya'da Zeus Stratios Kültü (111-113), 3.5. Zeus Horkios Kültü (113-114), 3.5.1. Kapadokya'da Zeus Horkios (Asbamaios) Kültü (114-121) şeklinde sıralanmaktadır.

Pers kökenli Zeus kültleri (69-70) ana başlıklı bölüm Pers etkisi altındaki Zeus inancına yer vermektedir. Pers hâkimiyeti Anadolu'da MÖ 546'dan itibaren etkisini göstermeye başlamıştır. Bu etkiyle beraber Pers kültürünün ve inancının kendini göstermesi sonucunda Ahura Mazda, Mithra, Anaitis, Vohu Monah gibi Pers tanrıları Anadolu'da tanınmaya başlamaktadır. Bu tanrıların isimleriyle veya Persçe ifadelerden oluşan epitetlerle Anadolu'da Zeus inancı şekillenmektedir. Antik dünyanın diğer inançlarından biri olan, monoteist niteliği ile diğer inanç sistemlerinden farklılık gösteren Zoroastrianizm, Mazdaizm ya da çok bilinen adıyla Zerdüştlük dinine de konuyla ilişkili olarak yer verilmektedir.

Pers hâkimiyetinin sona ermesinin ardından bölgede etkisini göstermeye başlayan Hellenistik kültüre ve aynı zamanda Pers kültürüne dair de bir kanıt niteliği taşıyan Bünyan Altarı (80-84), Arabsun Yazıtı (84-87) ve Kirdir Altarı (93) betimlenerek açıklanmaktadır.

Zeus Ahura Mazda Kültü (70), Ahura Mazda ve Dini (70-76) Pers etkisi altındaki tanrının önemini daha da vurgulamaktadır. Ahura Mazda olarak tapınım gören tanrı kadar Mithra inancı da çağlar boyunca varlığını sürdürmüştür. Zeus Mithra Kültü (93), tapınım gördüğü İran topraklarından Anadolu'ya Hellen ve Roma uygarlıklarına kadar yayılım gösteren Mithra ve Inancı (93-97) bir gizem dini olarak nitelendirilmektedir. Ahura Mazda tapınımında olduğu gibi Kapadokya'da Zeus Mithra Kültü (97-98) özellikle Hellen ve Roma tanrıları ile bir tutulur ya da asimilasyona uğrar. Mithra Roma'da Sol Invictus şeklinde karşımıza çıkarken Anadolu'da Men, Attis, Apollon, Helios ve Zeus ile eş değer ya da beraber görülmektedir. Kapadokya'da Roma'nın bir eyaleti olmasıyla birlikte sikkelerde yer alan motifleriyle de karşılaşılmaktadır. Bölgenin Pers etkisi altında olması ve synkretik yapısı nedeniyle Zeus'un Mithra ve Ahura Mazda'yı temsil ettiği düşünülmektedir. Okuyucuya Mithra inancı ile ilişkili olarak Farasa Yazıtı (98-99), Tyana Yazıtı (99-101), Kayseri Yazıtı (101-102), Camihöyük Mithra Maskesi (102-104) hakkında bilgiler aktarılmaktadır.

Zengin bir kült merkezi olan Kapadokya Bölgesi Hellen tanrıları ve Pers tanrılarıyla beraber büyük bir inanç kaynaşmasına ev sahipliği yapmaktadır. Bu kült çeşitliliğine dahil olan bir kültten 
daha bahsedilmektedir: Kapadokya'da Thymnasalı Zeus ve Zeus Pharnaousas Kültü (104-107). Eserden Zeus'un sıfatları içerisinde Anadolu'da şimdiye kadar Zeus ile ilgili kullanımı bilinmeyen iki farklı epitet ile ilgili çeşitli bilgiler edinmek mümkündür. Zeus Stratios Kültü (107-111) tanrının savaş̧̧ özelliği ile ilgili olan stratios epitetini taşımakta ve burada kültle beraber, Zeus Ahura Mazda'nın Hellenleştirilmiş epiteti olarak kabul gören Stratios epiteti açıklanmaktadır. Kapadokya'da Zeus Stratios Kültü’nün (111-113) ise çift cinsiyetli bir tanrıyı ima ettiğinden ve bununla ilgili çeşitli görüşlerin olduğundan bahsedilmektedir. Başka bir kült olan, yeminlerin tanrısı anlamında Horkios epitetiyle nitelendirilen Zeus Horkios Kültü (113-114) Hesiodos, Homeros, Pausanias ve Euripides gibi antik yazarlardan yapılan alıntılara yer verilerek aktarılmaktadır. Kapadokya Bölgesi'nde ise tanrılara ve krallara edilen yeminin Hititler dönemine kadar gittiği bilinmektedir. Kapadokya'da Zeus Horkios (Asbamaios) Kültü (114-121) Tyana yakınlarında bilinmektedir ve Tyana yakınlarında görülen bu kült ve kültün adına ilişkin değişik bilgilere ulaşmak mümkündür.

Kültlere adını veren epitetler dört kategoride sınıflandırılmaktadır. Illk kategori dördüncü bölümde ayrıntılarına girilen Bir Tanrı Adından Kaynaklanan Zeus Kültleri'dir (121-122). Bu kategoriye 4.1 Zeus Sabazios Kültü (122-129), 4.1.1. Kapadokya'da Zeus Sabazios Kültü (129-132), 4.2. Zeus Uranios Kültü (132-133), 4.2.1. Kapadokya'da Zeus Uranios (Vanessa) Kültü (133-135), 4.3 Zeus Ammon Kültü (135-138), 4.3.1. Kapadokya'da Zeus Ammon Kültü (138-141) epitetli kültler girmektedir.

Zeus'un başka tanrı isimleriyle birleşen birçok epiteti vardır. Bir Tanrı Adından Kaynaklanan Zeus Kültleri (121-122) kategorisinde yazar bu nitelendirmeleri üç ana başlık altında toplamaktadır; Tanrıya verilen Hellen epitetleri Asklepios, Dionysos, Kronos, Uranios gibi tanrılardan gelenler, Ahura Mazda ve Mithra gibi Pers kökenli olanlar, son olarak da Ammon ve Serapis gibi Zeus'un Mısır kökenli nitelendirmeleri.

Kendi başına bir tanrıyı ifade eden ve Zeus ile birlikte anıldığı için bir bütünlük içerisinde görülen Sabazios epiteti Zeus Sabazios Kültü'ne (122-129) adını vermektedir. Tanrının taşıdığı bu epitetin isim anlamı ve işlevi anlatılmaktadır. Aynı zamanda antik yazarların Sabazios hakkında vermiş oldukları bilgiler ve Sabazios'un ikonografik özelliklerine değinilmektedir. Anadolu'da da tanrının yerel bir kült olduğunu öğrendiğimiz eser, Kapadokya'da Zeus Sabazios Kültü’nün (129132) geçerliliğinin en önemli simgelerinin Sabaziak bir el figürü ve epigrafik bilgeler olduğunu da okuyucuya göstermektedir. Bunun gibi Zeus Sabazios epitetine dair daha birçok bilgiye bu araştırmadan ulaşmak mümkündür.

Okuyucu, Eskiçağ’da coğrafya ve kültürlerin farklılığına rağmen inancın simgelerinin benzer oluşuna dayanarak tüm evreni kaplayan Uranos'un karşılıklarını ve epitetin tam olarak ilgili olduğu anlamları Zeus Uranios Kültü (132-133) alt başlığından öğrenebilmektedir. Yazar’ın eserinde yer verdiği antik yazar Strabon'un anlattıkları sayesinde ise Kapadokya'da Zeus Uranios (Vanessa) Kültü’nün (133-135) varlığına ilişkin verilere ve tanrının üstlendiği epitetin anlamlandırmaları hakkında bilgilere ulaşılabilmektedir.

Ammon, Mısır panteonunun başrolündeki tanrılardan biridir. Yazar, Zeus Ammon Kültü (135138) hakkında bilgi aktarırken, tanrının Mısır kökenli olmasını temel alarak Herodotos, Plutarkhos, Pindaros, Strabon, Sicilyalı Diodoros, Lucanus ve Platon gibi antik dönem yazarlarının Zeus Ammon'dan bahsettiğine de yer vermektedir. Hakman, bölge olarak ise Kapadokya'da Zeus Ammon Kültü'nün (138-141) varlığı konusundaki verileri nümismatik buluntulara dayandırarak anlatmaktadır. Yazar ayrıca bu tanrının burada kabul görüp görmediği ile ilgili önemli yorumlarda 
da bulunmaktadır.

Beşinci bölümün ikinci kategorisi içerisinde yer alan Bir Sifattan Kaynaklanan Zeus Kültleri (141) ana başlığı altında 5.1. Zeus Megistos Kültü (141-143), 5.1.1. Kapadokya'da Zeus Megistos Kültü (143-145), 5.2. Zeus Dakienos Kültü (145), 5.2.1. Kapaddokya'da Zeus Dakienos Kültü (145147), 5.3. Zeus Epikarpios Kültü (147-148), 5.3.1. Kapadokya'da Zeus Epikarpios Kültü (148-150), 5.4. Zeus Polioukhos Kültü (150-151), 5.4.1 Kapadokya'da Zeus Polioukhos Kültü(151-153), 5.5. Zeus Soteros Kültü (153-156), 5.5.1. Kapadokya'da Zeus Soteros Kültü (156-161) şeklinde beş alt alt başlık ve bu alt başlıklara bağı beş yan başlık bulunmaktadır.

Zeus'un yüceliğini ifade eden Megistos epiteti Zeus Megistos Kültü’ne (141) ismini vermektedir. Yazar bu epitet ile ilgili açıklamalarını, Kapadokya'da Zeus Megistos Kültü (143-145) ile ilgili bir bulgu olan Boztepe Altarı'nı betimleyerek ve üzerindeki yazııın çözümlemesine yer vererek epigrafik bir belge üzerinden yapmaktadır. Yazar yerli kültlere örnek teşkil eden Zeus Dakienos Kültü'ne (145) de değinmekte, antik yazar Strabon'un aktardıkları doğrultusunda ise Kapadokya'da Zeus Dakienos Kültü'yle (145-147) ilgili verilere de ulaşmamızı sağlamaktadır. Zeus'un epitetlerinin sınıflandırıldığı çalışmada dikkati çeken epitetlerden birisi de Zeus Epikarpios Kültü'dür (147-148). Topraktan elde edilen ürünlerin koruyucusu anlamına gelen bu epitet Kapadokya'da Zeus Epikarpios Kültü'nün (148-150) en erken dönemlerdeki tapınımlarında da bereket tanıısı olarak karşımıza çıkmaktadır. Kültün verilerini, epigrafik buluntuların yanı sıra sikkeler ve altarlar oluşturmaktadır. Zeus Polioukhos Kültü'nün (150-151) varlığının yanı sıra bu kültün üstlendiği roller ve epitetin anlamlarına yer verilmektedir. Kapadokya'da Zeus Polioukhos Kültü’nün (151-153) Caesarea'da görüldügünü ifade eden yazar bu kült ile ilgili kesin bilgi sahibi olunabilecek kaynağın ise "MS V. yüzyıl Hristiyan tarihçisi olan Salminus Hermias Sozomenus"un eseri olduğunu ifade etmektedir.

Bir Antroponym ve Toponymden Kaynaklanan Zeus Kültleri (161) kategorisini konu edinen altıncı ve son bölüm bu ana başık altında 6.1. Bir Antroponymden Kaynaklanan Zeus Kültleri (161), 6.1.1. Kapadokya'da Zeus Gordios Epekoos Kültü (161-163), 6.2. Bir Toponymden Kaynaklanan Zeus Kültleri (163), 6.2.1. Zeus Dolikhenus Kültü (163-166), 6.2.1.1. Kapadokya'da Zeus Dolikhenus Kültü (166-168), 6.2.2 Dağ Kültleri (168), 6.2.2.1. Zeus Olybreus Epekoos Kültü (168169), 6.2.2.1.1. Kapadokya'da Zeus Olbreus Epekoos Kültü (169-170), 6.2.2.2. Zeus Argaios Kültü (170), 6.2.2.2.1. Kapadokya'da Argaios Kültü (170-183), 6.2.2.2.2. Kapadokya'da Zeus Argaios Kültü (183-197) sıralamasıyla iki alt başlık ve bu alt başlıklara bağlı bulunan yan başıklardan oluşmakta, Sonuç (197-201) ve Kaynakça (201) ile eser noktalanmaktadır.

Bir Antroponymden Kaynaklanan Zeus Kültleri'nin (161) isimlerini aldığı epitetler, bir antroponym'den alınmış oldukları için dikkat çekmektedir. Bu şekilde oluşturulan epitetlerde yer alan isimler, çoğunlukla şehrin ya da kültün kurucusundan kaynaklanmaktadır. Antikçağda özellikle dağlar ve çeşitli nedenlerden dolayı önemli olan yerleşimler kutsal kabul edilmektedir. Dolayısıyla Bir Toponymden Kaynaklanan Zeus Kültü'nün (163) taşıdığı tanrı epitetleri topografik ve coğrafik durumlar ile ilişkilendirilmektedir. Bu sebeple yukarıda bahsi geçen Zeus Kültleri önce epitetlerini nereden aldıklarıyla irdelenirken, Kapadokya Bölgesi içerisinde saptanan Zeus Kültlerinin almış oldukları epitetler ise antroponym ve toponym bilim dalları temel alınarak açıklanmaktadır. Dağ Külteleri (168) ise isminden de anlaşılacağı üzere bir dağ tanrısı olarak nitelendirilen Zeus'un bölgesel olarak üstlendiği epitetlerle beraber açıklanmaktadır. Yazar bu epitetleri Zeus Olybreus yazıında olduğu gibi diğer yazıtları veya dağ tanrısı olarak Argaios kültünün 
en önemli kanıtı olarak gösterilen Caesarea sikkeleri gibi bahsi geçen tüm disiplinler ışığında okuyucuya açıklamaktadır.

Sonuç (197-201) olarak eser, Kaynakça'dan (201) önceki son dört sayfada toparlanmakta ve konunun tümü özetlenerek son bulmaktadır. Yazar Sonuç (197-201) kısmında, "bu çalışma ile Anadolu'nun birçok yerleşimi ve bölgesiyle bağlantılı, dış etkenlere karşı açık olan, birçok epitetinde synkretik yapı sergileyen ya da yerleşimlerin siyasi, sosyal ve ekonomik özelliklerine göre dağılım gösteren Zeus kültünün Kapadokya'daki varlığını ortaya koyduğundan ve Zeus kültünün bu yapısı ile Kapadokya'ya yakın yerleşimler ya da aynı epitetlerin görüldüğü bölgelerden, kökensel açıdan gösterdiği çeşitlilikten dolayı sıyrılmış, kendine özgü bir inanç dokusu oluşturduğundan" bahsetmektedir. 